\title{
Genome-wide characterization of MATE gene family and expression profiles in response to abiotic stresses in rice (Oryza sativa)
}

\author{
Zhixuan Du' ${ }^{1 \dagger}$, Qitao Su${ }^{2 \dagger}$, Zheng Wu' ${ }^{1}$, Zhou Huang ${ }^{1}$, Jianzhong Bao ${ }^{1}$, Jianbin $\mathrm{Li}^{1}$, Hang Tu${ }^{1}$, Chuihai Zeng ${ }^{1}$, \\ Junru Fu${ }^{1 *}$ and Haohua $\mathrm{He}^{1 *}$
}

\begin{abstract}
Multidrug and toxic compound extrusion (MATE) proteins are involved in many physiological functions of plant growth and development. Although an increasing number of MATE proteins have been identified, the understanding of MATE proteins is still very limited in rice. In this study, 46 MATE proteins were identified from the rice (Oryza sativa) genome by homology searches and domain prediction. The rice MATE family was divided into four subfamilies based on the phylogenetic tree. Tandem repeats and fragment replication contribute to the expansion of the rice MATE gene family. Gene structure and cis-regulatory elements reveal the potential functions of MATE genes. Analysis of gene expression showed that most of MATE genes were constitutively expressed and the expression patterns of genes in different tissues were analyzed using RNA-seq. Furthermore, qRT-PCR-based analysis showed differential expression patterns in response to salt and drought stress. The analysis results of this study provide comprehensive information on the MATE gene family in rice and will aid in understanding the functional divergence of MATE genes.
\end{abstract}

Keywords: MATE, Expression analysis, Phylogenetic analysis, Gene function, Abiotic stress

\section{Introduction}

Multidrug and toxic compound extrusion (MATE) transporters constitute a class of secondary active transporters widely present in archaea, bacteria, prokaryotic and eukaryotic cells, and rely on the electrochemical potential of sodium or hydrogen ions to excrete compounds for transport activity as part of a secondary active transport mode [18]. All MATE proteins have approximately $40 \%$ sequence similarity [13]. Currently, three-dimensional crystal structure data are available only for the bacterial NorM protein (a norfloxacin efflux protein). The NorM protein has twelve transmembrane domains, which are

\footnotetext{
*Correspondence: fujunru2002@163.com; hhhua64@163.com

†Zhixuan Du and Qitao Su contributed equally to this work

1 Key Laboratory of Crop Physiology, Ecology and Genetic Breeding, Research Center of Super Rice Engineering and Technology, Jiangxi Agricultural University, Nanchang 330045, China

Full list of author information is available at the end of the article
}

double-layered along the lipid plane and arranged into two bundles of six transmembrane helices (TM1-TM6 and TM7-TM12) to form a large open cavity exposed to the extracellular space [11, 19, 37].

The first MATE transporter (NorM) was identified from Vibrio paralyticus; this protein expels norfloxacin and ciprofloxacin out of cells in an energy-dependent manner [3, 29]. Mammalian MATE proteins were first identified in humans and mice (MATE1 and MATE2) [34]. Human MATE1 and MATE2 proteins are encoded by the $S L C 47 A 1$ and SLC47A2 genes, respectively [46], which are mainly expressed in the kidney and liver [50]. Mammalian MATE protein can be used as multispecific and electron-neutral transporters of organic cations, mediating the discharge of various organic cations and cationic drugs $[12,61]$.

In plants, members of the MATE protein family are extremely abundant [5], and participate in regulating

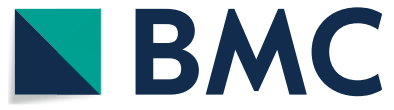

(0) The Author(s) 2021. Open Access This article is licensed under a Creative Commons Attribution 4.0 International License, which permits use, sharing, adaptation, distribution and reproduction in any medium or format, as long as you give appropriate credit to the original author(s) and the source, provide a link to the Creative Commons licence, and indicate if changes were made. The images or other third party material in this article are included in the article's Creative Commons licence, unless indicated otherwise in a credit line to the material. If material is not included in the article's Creative Commons licence and your intended use is not permitted by statutory regulation or exceeds the permitted use, you will need to obtain permission directly from the copyright holder. To view a copy of this licence, visit http://creativecommons.org/licenses/by/4.0/. The Creative Commons Public Domain Dedication waiver (http://creativeco mmons.org/publicdomain/zero/1.0/) applies to the data made available in this article, unless otherwise stated in a credit line to the data. 
plant growth and development processes. These processes include transporting secondary metabolites, toxic compounds and heavy metals; regulating disease resistance; and participating in plant hormone regulation. An Arabidopsis thaliana seed coat color mutant (tt12) has been identified. This phenotype is caused by the mutation of the TT12 gene, which is a member of the MATE family [6], and is responsible for regulating the transport and accumulation of proanthocyanidin in the seed coat cells to the vacuole [26]. The protein encoded by the barley MATE family gene $H v A A V T 1$ is located on the cell membrane and is mainly distributed in barley root tip epidermal cells; its substrate is citrate, which can increase resistance to aluminum [10]. The AltSB gene, which is involved in similar physiological mechanisms as those of aluminum tolerance, is also found in sorghum [25]. The tobacco gene Nt-JAT1 (Nicotiana tabacum jasmonate-inducible alkaloid transporter 1) encodes a protein located on the vacuolar membrane that can regulate the synthesis and transportation of nicotine and other alkaloids, effectively avoiding the toxicity of alkaloids to tobacco [28]. Overexpression of the ADP1-D gene inhibited the synthesis of auxin in Arabidopsis, resulting in a phenotype consisting of an abnormal plant height, an increased number of lateral branches and rosette leaves and no significant apical dominance [22]. The MATE gene overexpression mutant ads1-D in Arabidopsis (Activated Disease Susceptibility 1) has a reduced salicylic acid content, and is a sensitive to multiple pathogens [44]. Moreover, expression of the BIGE1 (Big Embryo 1) gene in maize accelerates leaf and root development and causes an enlarged embryo scutellum [27]. Over expression mutants of ZmMATE884 in Zea mays resulted in lower 1000-seed weight and smaller seed length than the wild type, indicating that ZmMATE884 gene involved in the regulation of plant seed size [56].

In rice, there are few studies on MATE genes, and their functions are poorly understood. The MATE gene OsFRDL1 encodes a citric acid transporter that is necessary for the efficient transport of iron to the stem in the form of an iron-citric acid complex in rice [59]. Similarly, OsFRDL4 (Os01g0919100) encodes an aluminuminduced citric acid transporter located in the plasma membrane of rice root cells and is one of the components of rice high aluminum tolerance [58]. Yokosho also revealed a MATE gene OsFRDL2 involvement in Al-induced secretion of citrate in rice [60]. In addition, MATE genes also mediate the defense response of rice, and OsMATE1 and OsMATE2 regulate the growth and development of plants and negatively affect disease resistance [48]. OSMATE2 also modulates arsenic accumulation in rice [32]. Transcriptomic data also show that these genes may be related to the stress response [48].
Recently, Qin et al. cloned a gene, DG1, that regulates rice grain filling, encoding a MATE transporter in rice. It has been illustrated that leaf-derived ABA controls rice seed development in a temperature-dependent manner and is regulated by DG1 [36].

Members of the MATE family participate in important regulation and control of the growth and development of organisms, but related functional studies of the rice MATE family members are still lacking, and no systematic analysis has been carried out. This study used bioinformatic methods to systematically analyze the chromosome distribution, physical properties, conservation, evolution and expression patterns of rice MATE family members, providing an important theoretical basis for the functional identification of MATE family members.

\section{Results}

Identification of the MATE genes in the rice genome

Via homology searches and domain (Pfam: PF01554) prediction, 46 genes encoding specific MATE proteins were ultimately identified in the rice genome. The genes were named OSMATE1-OSMATE46 according to their physical location on the chromosome. The length of the proteins encoded by these genes is between 370 and 598 aa, the molecular weight ranges from 39.41 to $61.65 \mathrm{kD}$, and the predicted isoelectric point ranges from 5.01 to 11.98 . Most of the proteins are neutral or partially alkaline. (Table 1).

\section{Chromosome distribution and replication pattern of the OsMATE genes}

The results of the OsMATE gene chromosome mapping show that 46 MATE genes are distributed across the 12 chromosomes of rice, but the distribution is uneven. Among them, chromosome 3 contains the largest number of MATE genes-a total of 10, and only one of the $M A T E$ genes is on chromosome 5 (Fig. 1A). There are 3 pairs of tandem repeat OsMATE genes (OsMATE21 and OsMATE22, OsMATE39 and OsMATE40, and OsMATE41 and OsMATE42) in rice, which are located on chromosomes 6,10 and 11, respectively, and there is a high similarity between the protein sequences within each gene cluster. In addition, 6 pairs of fragment repeat genes were detected (Fig. 1B). Taken together, these results indicate that tandem repeats and fragment replication contribute to the expansion of the rice MATE gene family.

\section{Phylogenetic analysis of the MATE family}

To study the phylogenetic relationship of rice MATE proteins, a phylogenetic tree was constructed using the MATE protein sequences of four different species 
Table 1 Details of the 46 MATE proteins in rice

\begin{tabular}{|c|c|c|c|c|c|}
\hline Ensemble ID & Gene name & Chromosome & Protein length (aa) & Molecular weight (Da) & Isoelectric point \\
\hline Os01t0504500 & OSMATE1 & 1 & 502 & 53543.6 & 5.41 \\
\hline Os01t0684900 & OSMATE2 & 1 & 491 & 52984.2 & 7.15 \\
\hline Os01t0766000 & OSMATE3 & 1 & 546 & 58346.1 & 9.83 \\
\hline Os01t0919100 & OSMATE4 & 1 & 598 & 61652.2 & 9.05 \\
\hline Os02t0122200 & OSMATE5 & 2 & 477 & 50490.4 & 8.54 \\
\hline Os02t0676400 & OSMATE6 & 2 & 549 & 57831.5 & 7.35 \\
\hline Os02t0821600 & OSMATE7 & 2 & 491 & 52508.1 & 5.21 \\
\hline Os03t0188100 & OSMATE8 & 3 & 489 & 52964.1 & 7.32 \\
\hline Os03t0216700 & OSMATE9 & 3 & 571 & 59963.9 & 8.36 \\
\hline Os03t0229500 & OSMATE10 & 3 & 602 & 61512.9 & 7.47 \\
\hline Os03t0570800 & OSMATE11 & 3 & 500 & 53838.9 & 7.35 \\
\hline Os03t0571700 & OsMATE12 & 3 & 370 & 39408.6 & 5.66 \\
\hline Os03t0571900 & OSMATE13 & 3 & 520 & 55795.1 & 5.01 \\
\hline Os03t0572900 & OsMATE14 & 3 & 500 & 53622.7 & 6.96 \\
\hline Os03t0626700 & OSMATE15 & 3 & 477 & 51833.8 & 8.92 \\
\hline Os03t0839200 & OSMATE16 & 3 & 516 & 53507.3 & 7.28 \\
\hline Os03t08588800 & OSMATE17 & 3 & 479 & 50620.2 & 10.07 \\
\hline Os04t0373400 & OSMATE18 & 4 & 483 & 50960.8 & 7.58 \\
\hline Os04t0571600 & OSMATE19 & 4 & 560 & 59186.8 & 6.74 \\
\hline Os05t0554000 & OSMATE2O & 5 & 500 & 53486.3 & 7.38 \\
\hline Os06t0494400 & OSMATE21 & 6 & 490 & 52046.9 & 6.51 \\
\hline Os06t0495500 & OSMATE22 & 6 & 479 & 51117.8 & 7.93 \\
\hline Os06t0558300 & OSMATE23 & 6 & 568 & 58865.9 & 7.19 \\
\hline Os06t0707100 & OsMATE24 & 6 & 483 & 51956.8 & 6.74 \\
\hline Os07t0108200 & OSMATE25 & 7 & 486 & 52845.4 & 6.98 \\
\hline Os07t0502200 & OSMATE26 & 7 & 482 & 51372.7 & 8.04 \\
\hline Os07t0516600 & OsMATE27 & 7 & 493 & 51871.5 & 8.46 \\
\hline Os08t0480000 & OsMATE28 & 8 & 489 & 52549.5 & 6.51 \\
\hline Os08t0545900 & OSMATE29 & 8 & 536 & 55666.9 & 8.35 \\
\hline Os08t0550200 & OSMATE3O & 8 & 522 & 56172.4 & 7.22 \\
\hline Os08t0562800 & OsMATE31 & 8 & 451 & 47495.5 & 5.57 \\
\hline Os09t0468000 & OSMATE32 & 9 & 482 & 51985.9 & 8.97 \\
\hline Os09t0524300 & OSMATE33 & 9 & 541 & 56434.6 & 7.55 \\
\hline Os09t0548300 & OSMATE34 & 9 & 577 & 60065.4 & 9.64 \\
\hline Os10t0190900 & OSMATE35 & 10 & 417 & 46361.6 & 11.98 \\
\hline Os10t0195000 & OSMATE36 & 10 & 464 & 50215.8 & 8.73 \\
\hline Os10t0206800 & OsMATE37 & 10 & 537 & 57722.7 & 6.92 \\
\hline Os10t0344500 & OSMATE38 & 10 & 519 & 54761.9 & 8.32 \\
\hline Os10t0344900 & OSMATE39 & 10 & 477 & 50734.7 & 8.55 \\
\hline Os10t0345100 & OSMATE4O & 10 & 479 & 50790.6 & 8.31 \\
\hline Os11t0126100 & OSMATE41 & 11 & 497 & 54675.9 & 6.75 \\
\hline Os11t0129000 & OsMATE42 & 11 & 470 & 51570.6 & 8.64 \\
\hline Os12t0106600 & OsMATE43 & 12 & 550 & 58374.2 & 5.14 \\
\hline Os12t0126000 & OsMATE44 & 12 & 507 & 55443.7 & 6.39 \\
\hline Os12t0552600 & OsMATE45 & 12 & 472 & 49684.5 & 8.12 \\
\hline Os12t0615700 & OSMATE46 & 12 & 500 & 54101.2 & 6.75 \\
\hline
\end{tabular}



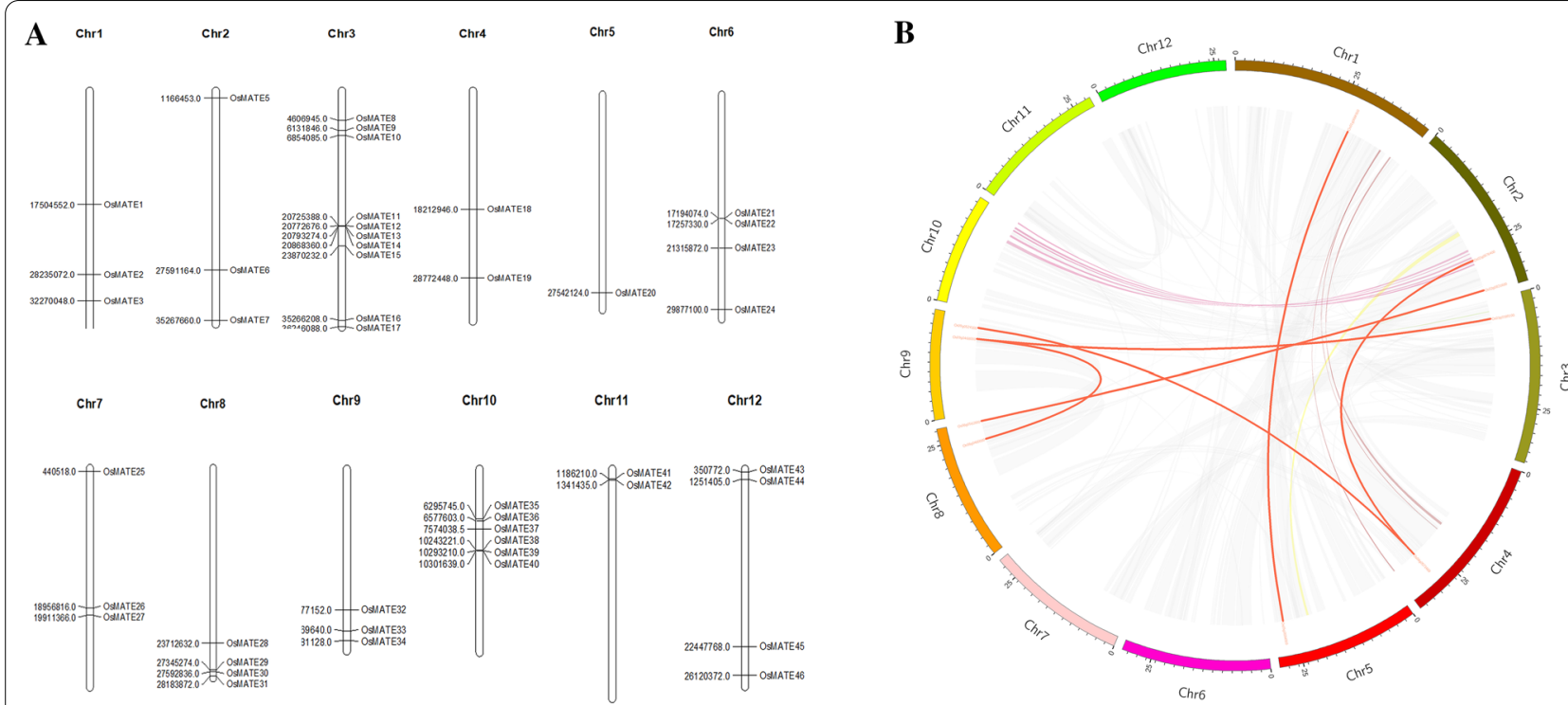

Fig. 1 Chromosomal location and gene segmental duplication of OSMATE. A Chromosomal distribution of rice MATE genes. B Distribution of segmentally duplicated MATE genes in the rice genome. The segmental duplication gene pairs were linked by the lines between chromosomes

(rice, maize, cotton and Arabidopsis) (Fig. 2). According to the topology of the evolutionary tree, 46 rice MATE proteins could be grouped into four groups. The first group contains the largest number of MATE proteins, a total of 18 , followed by the second group, which contains 13 MATE proteins. According to the phylogenetic relationship of the protein sequences, the functions of plant MATE proteins with known functions can be used to predict the functions of rice MATE proteins.

The first group contains 18 rice MATE proteins and several known genes, including AT3G59030 (AtTT12) [6], AT4G25640 (AtFFT) [47] and others. The function of the known MATE transporters in this branch suggests that members of the MATE subfamily I may be involved in the transport and accumulation of plant flavonoids, anthocyanins or alkaloids. The second group contains 13 rice MATE proteins. According to genes with known functions, the members of MATE subfamily II mainly transport multiple complexes [21]. The third group includes nine MATE proteins. The members of this group of known MATE proteins have many different functions, including disease resistance, organogenesis, iron ion homeostasis regulation, and leaf senescence $[4,54]$. The fourth group contains 6 MATE proteins. OsMATE4 and OsMATE9 have been found to participate in the secretion of citric acid in the root tips or in the transport of metal ions, indicating that these proteins are likely to participate in the physiological process of metal ion detoxification [58].

\section{Gene structure and conserved motifs of the OSMATE gene family}

The evolution of a family is mainly manifested as the diversity of gene structures and changes in conserved motifs. To better understand the structure of the rice $M A T E$ genes, the exon-intron structure of the OsMATE genes was analyzed using the annotation information of the rice reference genome (Fig. $3 \mathrm{C}$ ). The OsMATE genes were found to contain 1 to 14 exons, which is similar to the clustering results of the evolutionary tree. Genes in the same group often have similar structures but vary in their length of introns. Most genes in group I contain 7 or 8 exons, but OsMATE3O and OsMATE31 contain only 3 exons; moreover, the intron length of the genes in this group varies greatly. The genes in group II have 6-8 exons, but the length of their introns is shorter than that of many genes in group I. The group III genes have the fewest number of exons, with only 1 or 2 , and the length of the exons is longer than that of the members in the other three subgroups. The group IV genes have the largest number of exons (7-13). Similar results were also found in other studies $[17,42]$. It has also been found that exon-intron patterns within the same phylogenetic classification group showed great similarity. This may be the result of replication of these sequences, which may also prove that the classification results are reliable.

The MEME online prediction tool was used to identify the conserved motifs in the rice MATE proteins (Fig. 3B). A total of 10 conserved sequences (motifs 1-10) were identified. The results showed that all the 


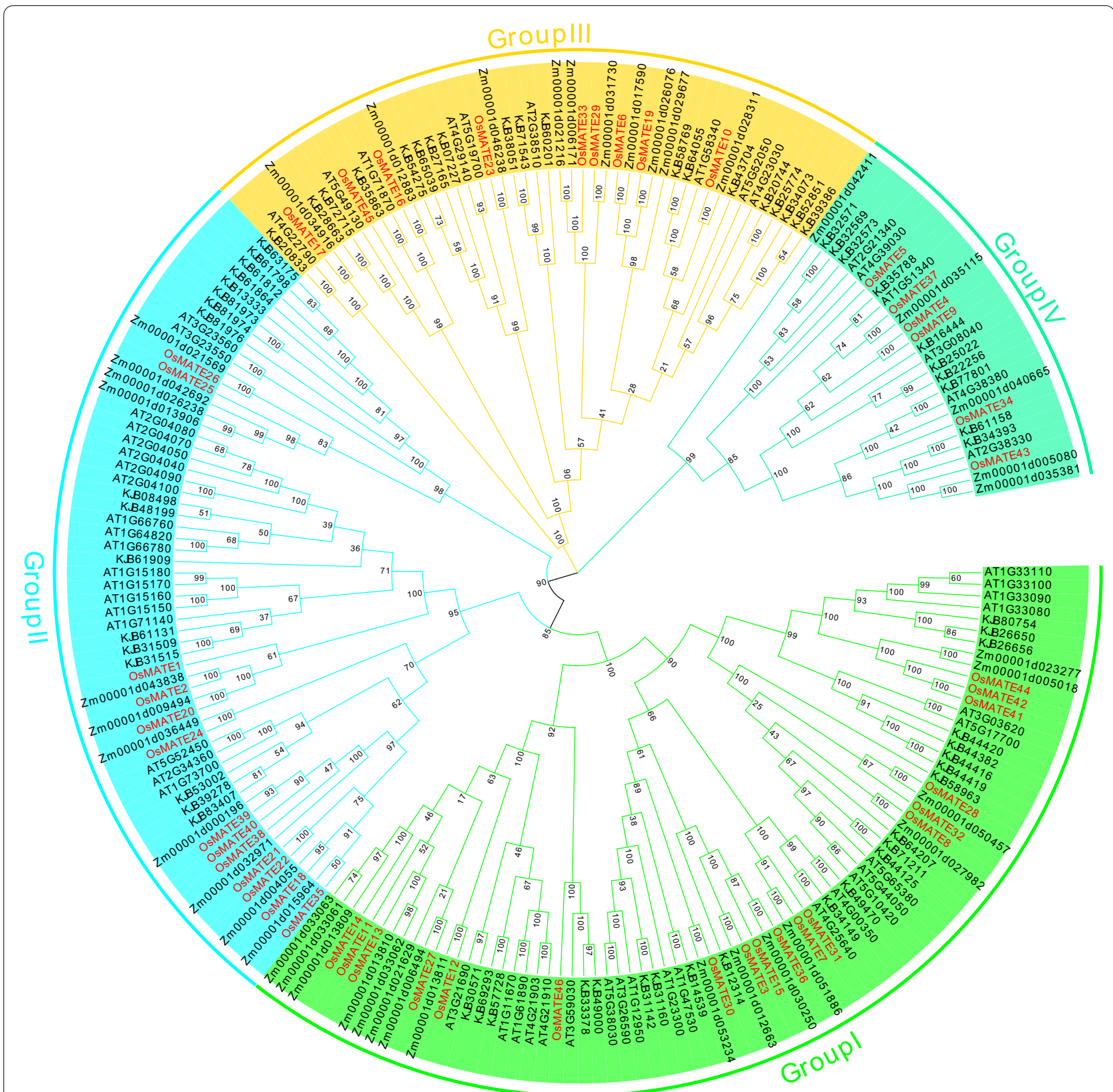

Fig. 2 The phylogenetic tree of MATE family. The phylogenetic tree was constructed by MEGA 6.0 using the Maximum Likelihood (ML) method. Bootstrap values in percentage (1000 replicates) are indicated on the nodes. Different subfamilies are highlighted using different colors. Zm is Zea maize, At is Arabidopsis, KJB is Gossypium spp.

rice MATE proteins contained at least 2 conserved motifs, and most MATE proteins (54\%) contained all the conserved motifs. Most proteins in subfamilies I, II, and III contain similar types and numbers of conserved motifs, but there are significant differences from the proteins in the fourth group. The MATE proteins in the fourth group contained only 2 to 3 conserved motifs, and the number of motifs was significantly lower than the number of proteins in the first three groups (Fig. 3B). These findings are similar to the prediction results of the conserved motifs of the MATE proteins in soybean [23], which may indicate that the function of the protein in the fourth group is more differentiated than that of the other three groups of members. 


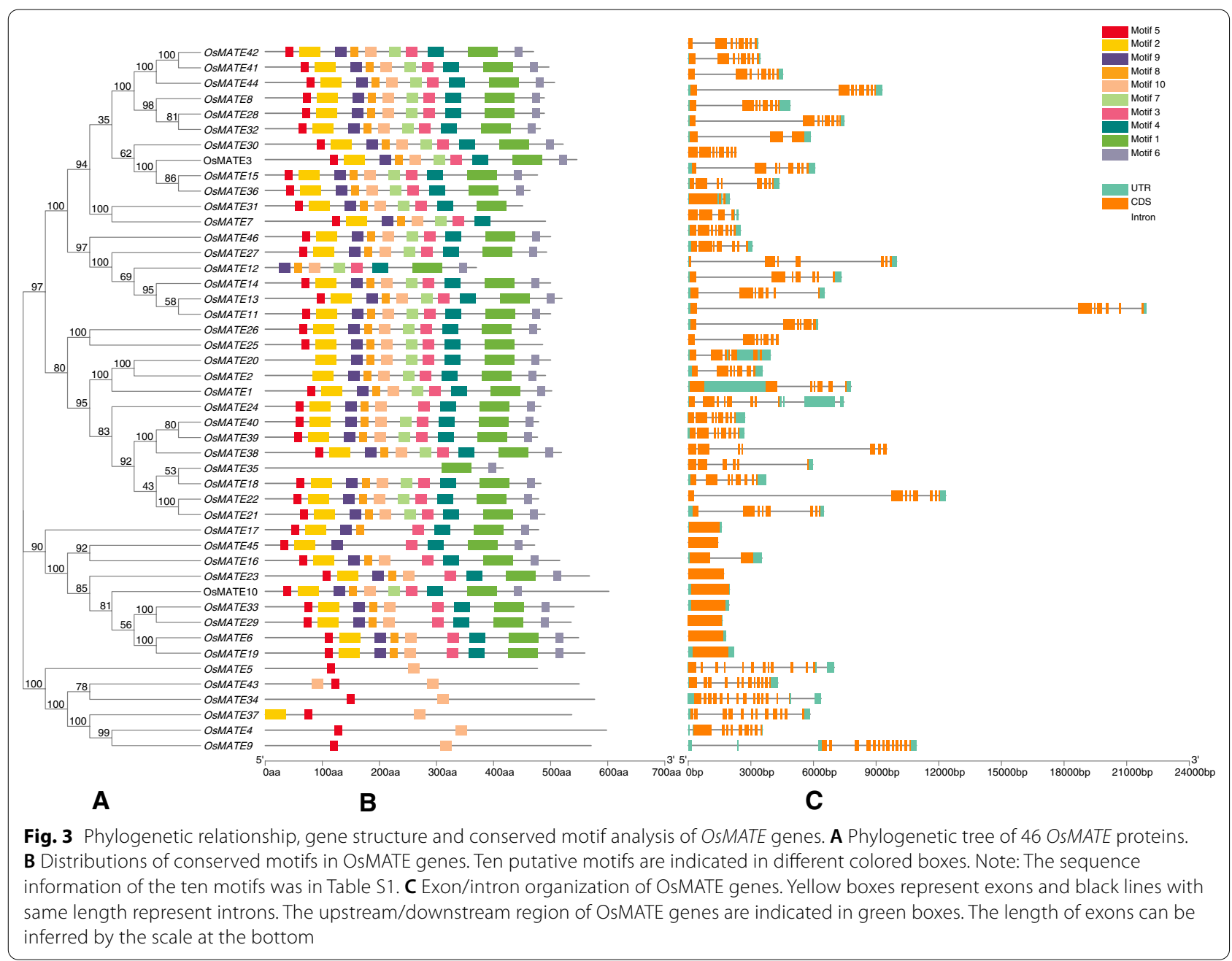

\section{Characterization of putative cis-regulatory elements in the promoter regions of OsMATE genes}

Cis-regulatory elements in the promoter regions play important roles in the plant response to stress. Using the PlantCARE database, we identified 11 putative stress-responsive cis-regulatory elements 1500 bp upstream of these OSMATE genes, including ABREs (ABA-responsive elements), TGACG motifs, CGTCA motifs (which are involved in the MeJA response), LTRs (low-temperature-responsive elements), MYBs, MBSs (MYB-binding sites), TCA elements (which are involved in salicylic acid responsiveness), TC-rich repeats (defense- and stress-responsive elements), WUN motifs (wound-responsive elements), GARE motifs (gibberellin-responsive elements) and AREs (anaerobic-responsive elements). The elements associated with the highest number of stress response elements within the OSMATE gene family are abscisic acid stress-related regulatory elements (ABREs) and drought-related elements (MYBs, MBSs) (Fig. 4). ABA is synthesized mainly in response to drought and high salinity stress. Among the elements, the number of defense- and stress-related response elements (TC-rich repeats) is the smallest. In addition, there are regulatory elements related to anaerobic stress (AREs), lowtemperature response elements (LTRs), and hormone response elements (TGACG motifs, CGTCA motifs, GARE motifs and TCA elements, etc.). Most of the proteins in subfamily I, II and III contain similar types and numbers of conserved motifs, but are significantly different from the fourth group of proteins. The 6 MATE proteins in the fourth group only contain 2 to 4 conserved motifs, the number of motifs is significantly less than the proteins in the first three groups, and they only contain 3 motif types. It may reflect that the function of the protein in the fourth group is more differentiated than the other three groups. These results showed that the rice MATE genes and stress-related response elements are relatively complete, but the type and number of stress-related elements contained in each MATE 


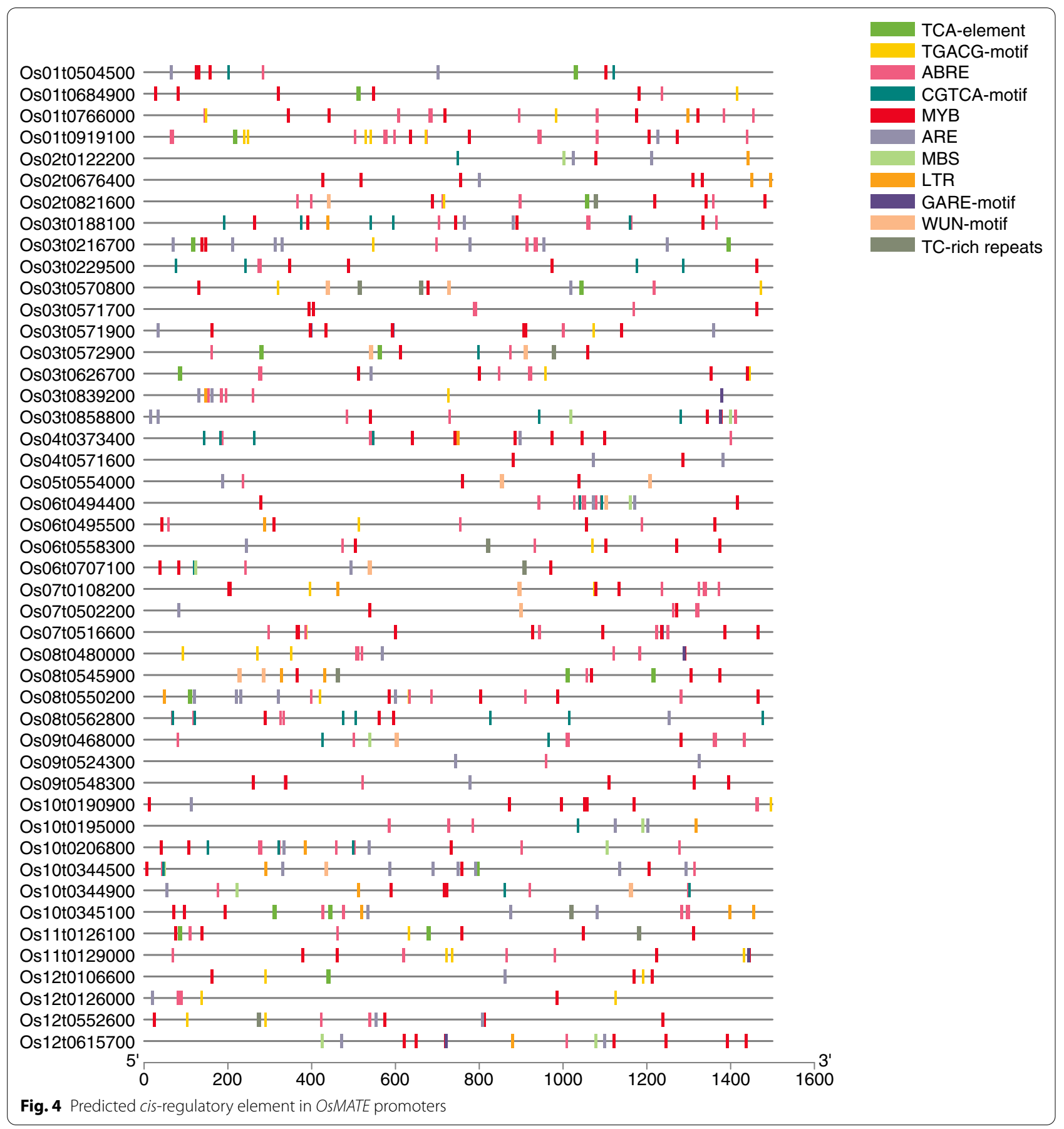

gene promoter differ, indicating that members of the rice MATE gene family can respond differently to different stresses.

\section{Expression patterns of OsMATE genes in different tissues}

Via RNA-seq data, heat maps of 43 MATE genes represented by FPKM values in different tissues and organs were constructed. A heatmap of gene expression was generated from a representative sample of 10 different organs (Fig. 5). All OsMATE genes were expressed, while a few (MATE4, MATE32, and MATE38) were expressed only in one tissue or organ. The number of gene families with members expressed in the leaves is the largest. Eleven genes, MATE1, MATE5, MATE14, MATE20, MATE24, MATE25, MATE26, MATE31, MATE34, MATE37 and MATE40, were expressed in all 


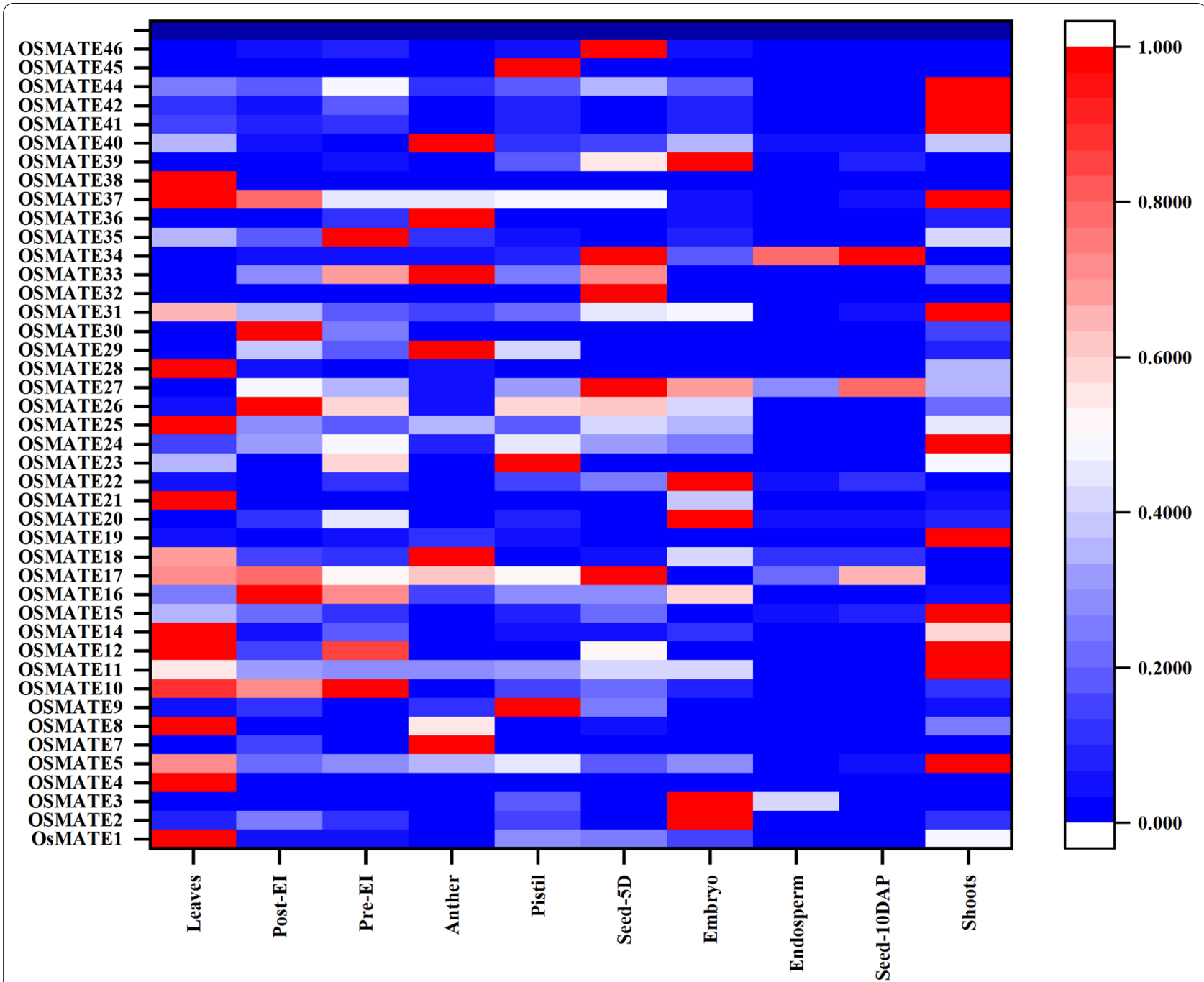

Fig. 5 Expression pattern of rice MATE genes. Expression level is expressed by color and intensity: dark red indicates highest expression level, dark blue indicates lowest expression level. Other colors represent intermediate levels of expression

of the tissues and showed constitutive expression. Some OsMATE genes showed similar expression patterns in various tissues. MATE41, MATE42 and MATE44, which were placed in the first group in the phylogenetic analysis, showed relatively high expression levels in the shoots. MATE2 and MATE39 of the second gene family in the phylogenetic analysis were highly expressed in embryos, and MATE19 and MATE45 exhibited high expression levels in the pistil. The expression in different plants parts is closely related to the functions of genes.

\section{Expression analysis of the OsMATE genes in response to abiotic stress}

Crop production and yield quality in most farmlands are severely affected by salt and drought stresses. To further explore the expression changes in MATE genes in response to various abiotic stresses, including salt and drought, we randomly used eight OsMATE genes from the four phylogenetic groups. qRT-PCR was used to measure the transcript levels of the OsMATE genes. The expression levels of the MATE genes under salt and drought stresses varied among the eight members (Figs. 6 and 7). MATE42 and MATE46 were downregulated after treatment. The remaining OsMATE genes were upregulated under salt stress, but the changes were not as extreme as those under drought stress. The expression of four genes (MATE2, 4, 16 and 45) reached the highest level for $24 \mathrm{~h}$ after salt stress, but the expression of two genes increased sharply for 3-6 h after salt stress. The OsMATE genes were sensitive to drought stress, 


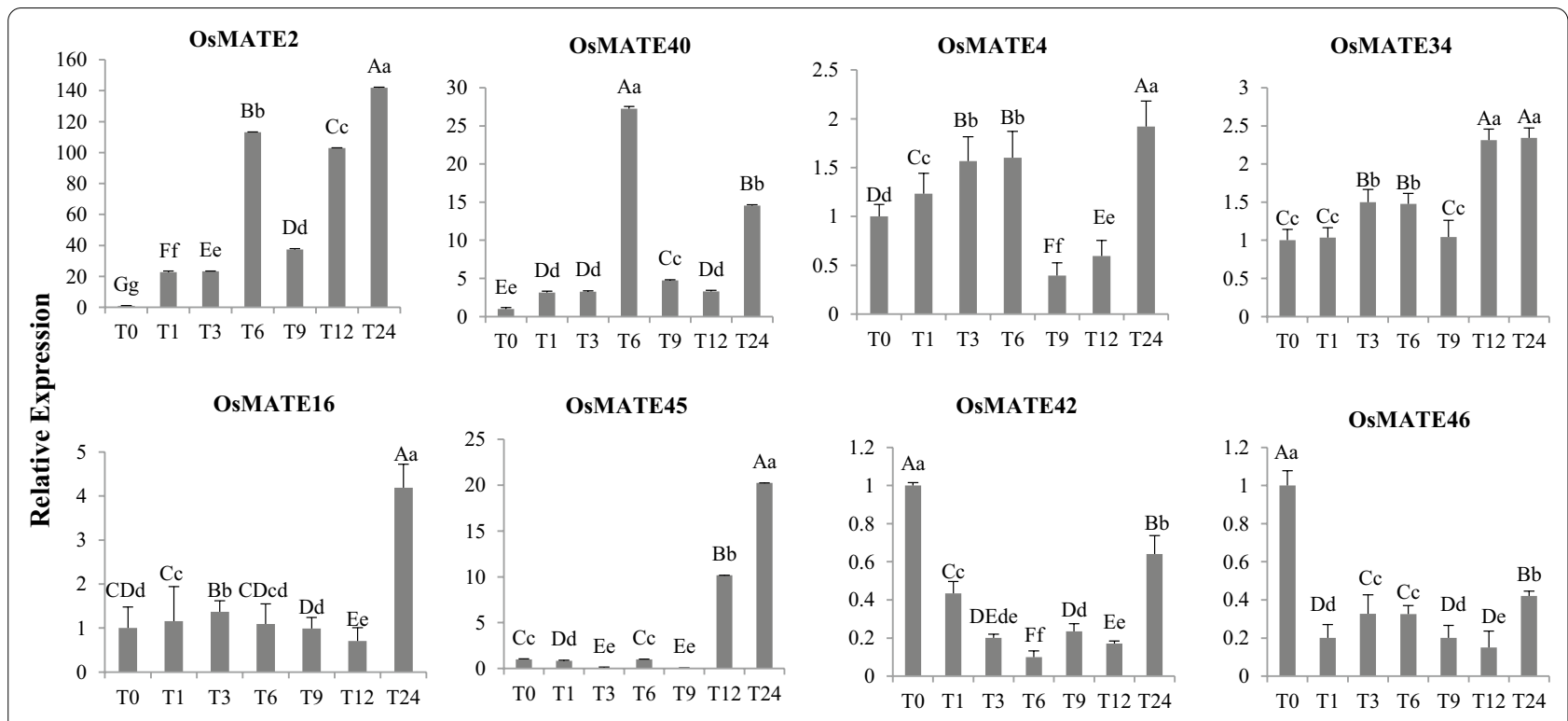

Treatment time(h)

Fig. 6 Expression pattern of genes after salt stress. Eight OSMATE genes representing four subfamilies were randomly selected and their relative expression in different periods was verified by qRT-PCR. The gene before treatment was used as an internal control, and its relative expression was one. All data were normalized. T0 represents before stress treatment. T1,T3, T6, T9, T12 and T24 represent 1, 3, 6, 9, 12 and $24 \mathrm{~h}$ after stress treatment, respectively. T The expression levels were represented by mean \pm SE. Error bars were obtained from three measurements. Small letters and capital letters above the bars indicated significant differences ( $p<0.05$, Duncan) and ( $p<0.01$, Duncan) respectively between different time stages

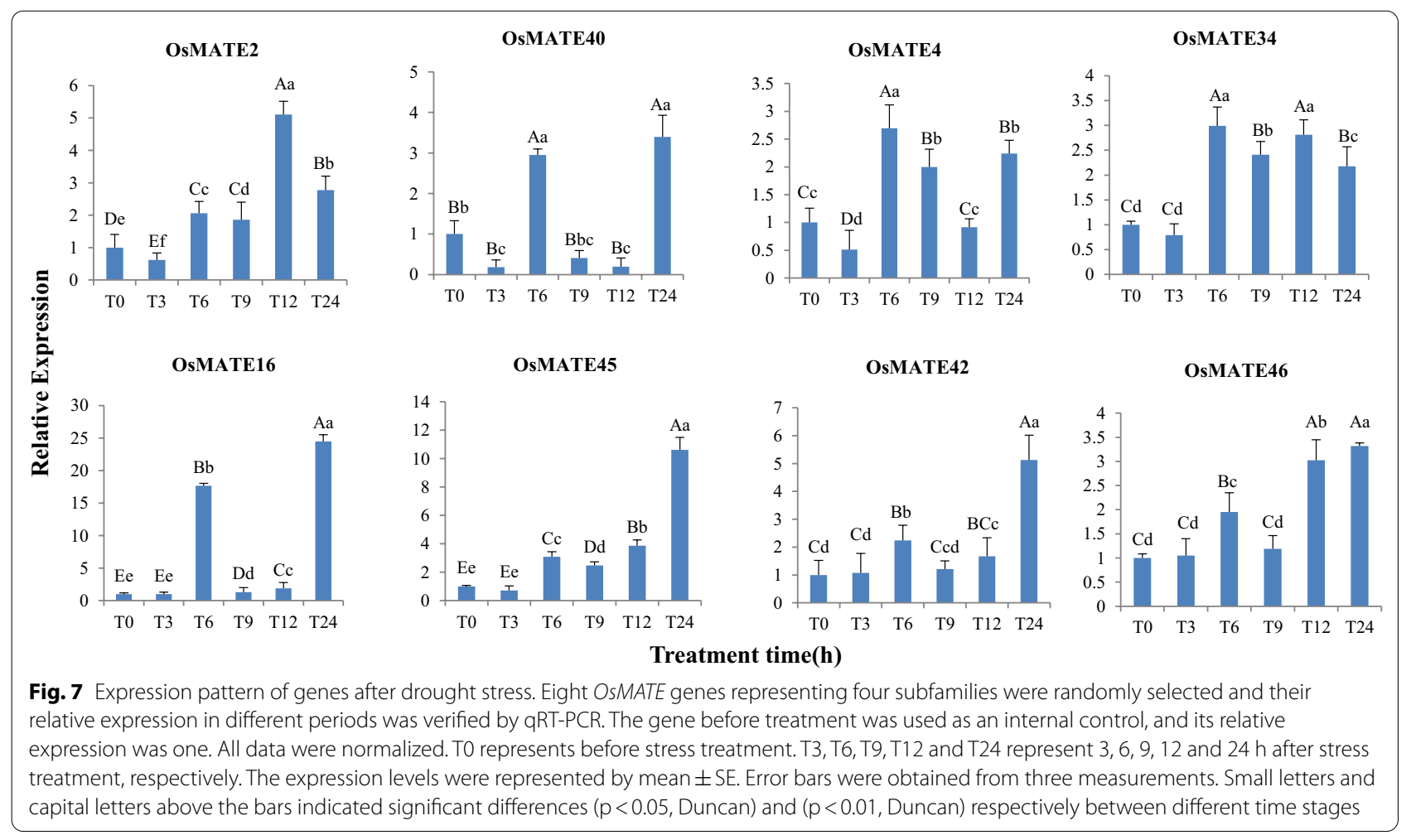


with none being downregulated. Notably, the expression level of all genes increased significantly for six hours after drought treatment. There were different responses and regulatory mechanisms of the MATE family members under various abiotic stress conditions.

MATE2 and MATE4 belong to the first group, and their expressions increased sharply $6 \mathrm{~h}$ after salt stress. The expressions of MATE4 and MATE34 in the second group did not change significantly after different treatment times. The expression levels of MATE16 and MATE45 were lower in the early stage of salt treatment and drought treatment, and reached the peak $24 \mathrm{~h}$ after treatment. The expression of two genes in the fourth group, MATE42 and MATE46, decreased after salt stress.

\section{Discussion}

The MATE gene family comprises one of the largest family of genes that encode transporters in plants, and the members are involved in many physiological processes during plant growth and development. At present, the structure and function of the members of the MATE transporter family have been analyzed in many plant species, such as Arabidopsis [6, 21], soybean [23], tomato [42], and sesame [17]; however, this information has been less reported in rice [15].

The MATE family of genes has a large number of stress response elements, including elements that respond to low temperature, drought [31], mechanical damage and hormones, and it has been shown that stress-related elements in the promoter regions of plants under adverse conditions can improve gene transcription and enhance the resistance of plants to adverse conditions [30, 35, 57].

Many functional gene families evolve and expand during gene replication. The MATE gene family has expanded mainly through tandem and segmental duplication events $[45,54]$. In contrast to the amplification pattern of the MATE gene family in tomato, tandem replication in the OSMATE gene family is less abundant. In rice, there was more fragment replication of the MATE genes, similar events occurred in the diploid cotton and soybean. Fragment replication was the main driving force for the amplification of the MATE gene family, which may be related to the multiple genome-wide replication events experienced by the genome during the evolutionary process.

Phylogenetic analysis is one of the most commonly used methods to predict gene function, which can provide a relatively reliable reference for further functional verification. In this study, by clustering with known plant MATE proteins, rice MATE proteins were divided into four groups, and most of the MATE proteins with different functions were grouped in different groups. These results are similar to the MATE gene classification of other species [23]. Some of the genes in the first group were highly expressed in the roots. The proteins in group I are mostly involved in the transport and accumulation of various plant secondary metabolites. For example, AtTT12 (At3g59030) encodes a protein that is localized on the vacuolar membrane and is involved in the transport of proanthocyanidin precursors into the vacuole, and the seed coat color of the mutant is lighter than that of the wild type [6]. The AtFFT protein is a flavonoid transporter that affects the level of flavonoids in Arabidopsis [47]. In other species, MATEs have similar functions. MtMATE1 is the key gene whose encoded protein is involved in transmembrane transport of original anthocyanins [62], and the protein encoded by MtMATE2 mediates vacuolar sequestration of flavonoid glycosides and glycoside malonates in Medicago truncatula [63]. Nt-mate1 and NT-MATe2 in tobacco mediate the transport and isolation of nicotine in the vacuole [49], and MdMATE1 and MdMATE2 of apple were grouped with AtTT12 in the phylogenetic tree. Both genes were transferred into $t t 12$ mutants of Arabidopsis to rescue the mutant phenotype to that of the wild type, indicating that MdMATE1 and MdMATE2 are the key genes involved in proanthocyanidin transport in apple [9]. Similarly, in grape, VvMATE1 and VvMATE2 regulate the transport of procyanidins during berry development [38].

Proteins in the second group mediate the transport and efflux of multiple complexes and toxins. For example, AtALF5 (At3g23560) is associated with plant resistance to toxins in Arabidopsis. Alf5 mutants are unable to form lateral roots, and their roots are more sensitive to multiple complexes than are wild-type roots [7]. AtDTX1(At2g04040), the first cloned plant MATE gene, has been identified as encoding a detoxifying efflux carrier for plant-derived antibiotics and other toxic compounds, including $\mathrm{Cd}^{2+}$ [21]. OsMATE2 in rice is upregulated in response to arsenic stress and predominately in developing seeds, regulating the transport and accumulation of arsenic in grains [32]. Tobacco NT-JAT1 has been shown to encode a nicotine transporter that is involved in the deposition of alkaloids in the vacuole [28]. Some genes in the second group are highly expressed in embryos and may be involved in the regulation of seed development.

The third group contained many known genes involved in a variety of physiological processes, including disease resistance, organogenesis, ion transport and leaf senescence. For example, AT4G29140 encodes activated disease susceptibility 1 (ADS1), a putative MATE transport protein that negatively regulates plant disease resistance and the elongation of hypocotyl cells [41]. ZF14 encodes a plant MATE transporter that is localized to the Golgi complex and other small organelles and is involved in 
determining the rate of organ initiation; this gene is also involved in iron homeostasis when plants are under osmotic stress [4]. ELS1 is related to the senescence of Arabidopsis leaves [54]. Bige1(Zm00001d012883) encodes a trans-Golgi apparatus-related transporter that is involved in regulating organ structure and size. Loss of Bige1 function leads to increased embryo size and accelerated production of lateral organs, including both leaves and roots, as well as early flowering [27]. RNA sequencing also showed that some of the genes in the third group were highly expressed in the pistil and are involved in $\mathrm{Fe}$ nutrition during organ initiation and development.

In the fourth group, the MATE proteins are known to be involved in metal ion transport. Arabidopsis EDS5(enhanced disease susceptibility 5), which is a chloroplast- localized salicylic acid transporter, is an essential component of salicylic acid-dependent signaling needed for disease resistance and expression induced by salicylic acid [33, 43]. MATE transporters transport iron by transporting citric acid and protocatechuic acid, which can chelate Fe ions and increase their solubility. OsFRDL1 (Os03g0216700) is a citric acid transporter localized in pericycle cells and is necessary for the effective transport of iron to the stem in the form of iron-citric acid complexes [59]. FRD3 is likely to function in root xylem loading of iron chelators or other factors necessary for efficient iron uptake from the xylem or apoplastic space and into leaf cells $[39,40]$. OsFRDL4 is an aluminuminduced citric acid transporter localized in the plasma membrane of rice root cells and is one of the components involved in the high aluminum tolerance of rice [58]. Two MATE proteins, OsPEZ1 and OsPEZ2, were identified in rice as being essential to achieve Fe ion exudation by transporting phenolic compounds and protocatechuic acid $[2,16]$.

The gene structure analysis showed that the members of each group had similar exon-intron structures, but the gene structure of the members in the different groups were quite different, indicating that the members of the rice $M A T E$ gene family had differentiated into groups with different functions during the evolutionary process. The conserved base sequence prediction results also showed that rice MATE proteins in the different groups have different types and numbers of conserved motifs. In the first, second and fourth groups, MATE proteins contain a relative abundance of conserved motifs, which explains why the role of these transporter variations is relatively large. Substrate proteins may exert a variety of different functions and were present in the three groups of known plants; these proteins include MATE proteins involved in secondary metabolite transport and accumulation of a variety of external complexes, ion transport and organs, and a variety of physiological functions.
The third group had relatively few exons. In some studies, to respond to stress in a timely manner, genes must be activated quickly, aided by a compact structure with relatively few introns $[24,64]$. These properties were the same as those of the MATE genes in both cotton and maize[24, 64]. QRT-PCR clearly indicated that OsMATE genes play a significant role in tolerating the effects of salt and drought stress in rice. The response pattern is different, which shows that MATE genes have different regulatory pathways in response to abiotic stress.

\section{Conclusions}

Overall, in the present study, genome-wide analysis of 46 MATE genes identified in the rice genome and the comparison with homologous genes of other species revealed the potential function of these genes in transport. Given their important role in plant physiology, MATE transporters may be ideal targets for breeding programs to improve agricultural-related traits such as aluminum tolerance, iron nutrition and accumulation of secondary metabolites (such as increasing anthocyanin contents or eliminating toxic alkaloids).

\section{Materials and methods}

\section{Identification of MATE transporters in the rice genome}

Rice genomic data were downloaded from the Ensemble database (http://asia.ensembl.org/index.html). Using the sequence of the fifty-six Arabidopsis MATE protein sequences as the query sequence, BlastP was used to search the MATE family genes from the whole genome database of rice. The sequence of the conserved domain of the MATE proteins was determined via a hidden Markov model (HMM) (PF01554). We downloaded the HMM profile of MATEs from the Pfam protein family database [8], and used it as the query $(\mathrm{P}<0.001)$ to search the rice protein sequence data. After removing the redundant sequences, a total of 46 MATE family genes were identified. The NCBI CDD (https://www.ncbi.nlm.nih. gov/Structure/bwrpsb/bwrpsb.cgi), Pfam database and SMART database [20] (http://smart.embl-heidelberg.de/) were used to confirm the conserved domain. The theoretical isoelectric point (pI), the number of amino acids and the molecular weight (MW) of the MATE proteins were computed by ExPASy (http://web.expasy.org/protp $\operatorname{aram} /)$ [55].

\section{Chromosomal locations and gene duplication analysis}

The chromosomal locations of the OsMATE genes were illustrated by MapChart software 2.2 [51]. Segmental and tandem duplication events of the MATE family were identified using the Multiple Collinearity Scan tool kit (MCScan) [53] from the Plant Genome Duplication Database. Homologous genes $(\mathrm{E}<1 \mathrm{e}-40$, similarity $>50 \%)$ 
within 3 gene loci were considered tandem replication genes, and TBtools software was used to draw a schematic diagram of the positional relationship of the collinear genes.

\section{Phylogenetic analysis of MATE proteins}

Phylogenetic analysis was performed using the fulllength sequence of MATE amino acids from Arabidopsis, maize and cotton combined with the sequence of the newly identified OsMATE proteins. Multiple sequences were aligned by ClustalX software, with the default parameters. MEGA 6 software with 1000 bootstrap tests was used to construct an unrooted neighbor-joining phylogenetic tree.

\section{Gene structure and motif analyses}

Gene structure analysis was performed using the Gene Structure Display Server [14] (GSDS, http://gsds.cbi.pku.edu.cn/) program, with the default settings. Motifs within the MATE proteins were identified using MEME [1] (http://meme-suite.org/), with the default settings (motif width: between 6 and 50 (inclusive)). The maximum number of motifs was 10 .

\section{Analysis of cis-regulatory elements in the promoter regions of OsMATE genes}

The $1.5 \mathrm{~kb}$ upstream sequence of the MATE gene translation initiation codon was downloaded from the Phytozome database. Using the PlantCare database (http:// bioinforma-tics.psb.ugent.be/webtools/plantcare/html/), cis-regulatory elements in the $1500 \mathrm{bp}$ upstream region were subsequently predicted.

\section{Analysis of RNA sequencing (RNA-seq) data from the MATE family}

RNA-seq data were downloaded from the Rice eFP Browser (http://www.bar.utoronto.ca/efprice/cgi-bin/ efpWeb.cgi) to study the expression in various tissues and at various stages of reproductive development of rice. To render the data suitable for cluster display, the absolute FPKM value was divided by the average of all the values and then $\log 2$ transformed. Excel 2010 was used to perform data filtering and analysis. Origin software was used to generate a heatmap.

\section{Plant materials and abiotic stress treatments}

Changhui 121, a cultivated rice variety from Jiangxi province and bred by Jiangxi Agricultural University, was selected in the experiment. The mature seeds were placed in the petri dish, sterilized by $2 \% \mathrm{NaCLO}$, soaked at $30{ }^{\circ} \mathrm{C}$ for $48 \mathrm{~h}$, and then placed in a perforated PCR plate. A PCR plate was separated by placing 24 seeds as biological repeats. The treatment and control groups were repeated with two plates. All seedlings were placed in the growth chamber with 14-h day/10-h night photoperiod and a $26 / 24{ }^{\circ} \mathrm{C}$ (day/night) temperature cycle. Rice seeds were cultured in sterile water in first 3 days and then in Yoshida nutrient solution.

For salt stress, rice seedlings were cultivated in an artificial growth chamber to the three-leaf stage. Yoshida nutrient solution with a final $\mathrm{NaCl}$ concentration of 120 $\mathrm{mM}$ was used for stress treatment. For drought stress, the plants were treated with $15 \%$ PEG-6000 at 29 days after rice germination. Under these different stress conditions, the aboveground parts of whole plants were collected at $0,3,6,9,12$ and $24 \mathrm{~h}$ after treatment and immediately frozen in liquid nitrogen and stored at $-80^{\circ} \mathrm{C}$.

\section{RNA extraction and expression analyses of MATE genes}

In different stress treatments, three plant leaves with the same growth potential were taken for RNA extraction. Total RNA was extracted using an RNA Simple Total RNA Kit (Takara, Japan). First-strand cDNAs were synthesized using a PrimeScript First Strand cDNA Synthesis Kit (Takara) in a total of $20 \mu \mathrm{l}$ reaction volume consisting of $1 \mu \mathrm{g}$ of total RNA, $4 \mu \mathrm{l}$ of $5 \mathrm{X}$ Prime Script RT Master Mix, and RNAase-free ddH2O. The PCR program was as follows: $95{ }^{\circ} \mathrm{C}$ for $2 \mathrm{~min}$ followed by 40 cycles of $95^{\circ} \mathrm{C}$ for $5 \mathrm{~s}$ and $60^{\circ} \mathrm{C}$ for $30 \mathrm{~s}$.

Quantitative real-time PCR was performed on an ABI 7500 quantitative real-time PCR system following the manufacturer's instructions. Primer Premier 5 was used to design primers specific to the MATE genes (Additional file 1: Table S2). The Actin was used as a reference gene. QRT-PCR was performed in a final volume of $20 \mu \mathrm{l}$, consisting of $2 \mu \mathrm{l}$ of cDNA, $10 \mu \mathrm{l}$ of 2X SYBR Green Master Mix (Takara), and $1 \mu \mathrm{l}$ of forward and reverse primers. The amplification program was as follows: initial denaturation at $95{ }^{\circ} \mathrm{C}$ for $5 \mathrm{~min}$; 40 cycles of denaturation at $95^{\circ} \mathrm{C}$ for $10 \mathrm{~s}$ and annealing at $60{ }^{\circ} \mathrm{C}$ for $20 \mathrm{~s}$; and a final extension at $72{ }^{\circ} \mathrm{C}$ for $20 \mathrm{~s}$. Three biological replicates were performed, and three technical replicates were performed per cDNA sample. The relative expression values were calculated by $2^{-\Delta \Delta C T}$ method.

\section{Supplementary Information}

The online version contains supplementary material available at https://doi. org/10.1186/s12862-021-01873-y.

Additional file 1. The supplementary information of genome-wide characterization of MATE gene family and expression profiles in response to abiotic stresses in rice.

Acknowledgements

Not applicable. 


\section{Authors' contributions}

ZXD, QTS, ZW, and ZH carried out the data mining, bioinformatics, gene expression analysis, and drafted the manuscript. JZB, JBL, HT and JL performed the data analyses, stress treatment and RNA isolation. JRF and $\mathrm{HHH}$ carried out the revising process. All authors read and approved the final article.

\section{Funding}

This work is supported by the National Natural Science Foundation of China (31471441 and 30860136), Seven major crop breeding projects under the national Key Research and development program (2017YFD0100301) and Jiangxi major Science and Technology Project - Breeding of new green rice varieties with high quality.

\section{Availability of data and materials}

The datasets generated and/or analysed during the current study are available in the fishare repository, [https://figshare.com/articles/online_resource/the_ date_of_MATE_family_rar/14616717].

\section{Declarations}

Ethics approval and consent to participate

Not applicable.

\section{Consent for publication}

All the authors agreed to publish the manuscript.

\section{Competing interests}

The authors declare that they have no competing interests.

\section{Author details}

${ }^{1}$ Key Laboratory of Crop Physiology, Ecology and Genetic Breeding, Research Center of Super Rice Engineering and Technology, Jiangxi Agricultural University, Nanchang 330045, China. ${ }^{2}$ School of Life Sciences, Jinggangshan University, Ji'an 343009, China.

Received: 17 May 2021 Accepted: 29 June 2021

Published online: 09 July 2021

\section{References}

1. Bailey TL, Boden M, Buske FA, Frith M, Grant CE, Clementi L, Ren J, Li WW, Noble WS. MEME SUITE: tools for motif discovery and searching. Nucleic Acids Res. 2009;37:W202-8.

2. Bashir K, Ishimaru Y, Shimo H, Kakei Y, Senoura T, Takahashi R, Sato Y, Sato Y, Uozumi N, Nakanishi H. Rice phenolics efflux transporter 2 (PEZ2) plays an important role in solubilizing apoplasmic iron. Soil Sci Plant Nutr. 2011;57:803-12

3. Brown MH, Paulsen IT, Skurray RA. The multidrug efflux protein NorM is a prototype of a new family of transporters. Mol Microbiol. 1999;31:8.

4. Burko Y, Geva Y, Refael-Cohen A, Shleizer-Burko S, Shani E, Berger Y, Halon E, Chuck G, Moshelion M, Ori N. From organelle to organ: ZRIZI MATE-Type transporter is an organelle transporter that enhances organ initiation. Plant Cell Physiol. 2011;52:518-27.

5. Chen L, Liu Y, Liu H, Kang L, Geng J, Gai Y, Ding Y, Sun H, Li Y. Identification and expression analysis of MATE genes involved in flavonoid transport in blueberry plants. PLOS ONE. 2015;10:e118578.

6. Debeaujon I, Peeters A, Leon-Kloosterziel K, Koornneef M. The TRANSPARENTTESTA12 gene of Arabidopsis encodes a multidrug secondary transporter-like protein required for flavonoid sequestration in vacuoles of the seed coat endothelium. Plant Cell. 2001; 13:853-871.

7. Diener AC. Arabidopsis ALF5, a multidrug efflux transporter gene family member, confers resistance to toxins. Plant Cell. 2001;13:1625-38.

8. Finn RD, Bateman A, Clements J, Coggill P, Eberhardt RY, Eddy SR, Heger A, Hetherington K, Holm L, Mistry J, Sonnhammer EL, Tate J, Punta M. Pfam: the protein families database. Nucleic Acids Res. 2014;42:D222-30.

9. Frank S, Keck M, Sagasser M, Niehaus K, Stracke R. Two differentially expressed MATE factor genes from apple complement the Arabidopsis transparent testa12 mutant. Plant Biol. 2011;13:42-50.
10. Furukawa J, Yamaji N, Hua W, Mitani N, Murata Y, Sato K, Katsuhara M, Takeda K, Ma A. An aluminum-activated citrate transporter in barley. Plant Cell Physiol. 2007;8:7

11. He X, Szewczyk P, Karyakin A, Evin M, Hong W X, Zhang Q, Chang G. Structure of a cation-bound multidrug and toxic compound extrusion transporter. Nature. 2010; 467:991-994.

12. Hiasa M, Matsumoto T, Komatsu T, Moriyama Y. Wide variety of locations for rodent MATE1, a transporter protein that mediates the final excretion step for toxic organic cations. Am J Physiol Cell Physiol. 2006; 291:C678-86.

13. Hiroshi $\mathrm{O}$, Miki H, Takuya M, Masato O, Yoshinori M. The MATE proteins as fundamental transporters of metabolic and xenobiotic organic cations. Trends Pharmacol Sci. 2006;27:11.

14. Hu B, Jin J, Guo A Y, Zhang H, Luo J, Gao G. GSDS 2.0: an upgraded gene feature visualization server. Bioinformatics. 2015; 31:1296-7.

15. Huang J, An W, Wang K, Jiang T, REN Q, Liang W, Wang H. Expression profile analysis of MATE gene family in rice. Biol Plant. 2019;63:556-64.

16. Ishimaru Y, Kakei Y, Shimo H, Bashir K, Sato Y, Sato Y, Uozumi N, Nakanishi $\mathrm{H}$, Nishizawa NK. A rice phenolic efflux transporter is essential for solubilizing precipitated apoplasmic iron in the plant stele. J Biol Chem. 2011;286:24649-55

17. Junchao L, Jian S, Tingxian Y. Genome-wide identification and expression analysis of MATE gene family in sesame. Genom Appl Biol. 2019;10:784.

18. Kuroda T, Tsuchiya T. Multidrug efflux transporters in the MATE family. Biochim Biophys Acta. 2009; 1794:763-768.

19. Kusakizako T, Miyauchi H, Ishitani R, Nureki O. Structural biology of the multidrug and toxic compound extrusion superfamily transporters. Biochim Biophys Acta Biomembr. 2019;183:154.

20. Letunic I, Doerks T, Bork P. SMART: recent updates, new developments and status in 2015. Nucleic Acids Res. 2015;43:D257-60.

21. Li L, He Z, Pandey GK, Tsuchiya T, Luan S. Functional cloning and characterization of a plant efflux carrier for multidrug and heavy metal detoxification. J Biol Chem. 2002;277:5360-8.

22. Li R, Li J, Li S, Qin G, Novak O, Pencik A, Ljung K, Aoyama T, Liu J, Murphy A, Gu H, Tsuge T, Qu LJ. ADP1 affects plant architecture by regulating local auxin biosynthesis. PLoS Genet. 2014;10:e1003954.

23. Liu J, Li Y, Wang W, Gai J, Li Y. Genome-wide analysis of MATE transporters and expression patterns of a subgroup of MATE genes in response to aluminum toxicity in soybean. BMC Genom. 2016;17:223.

24. Lu P, Magwanga RO, Guo X, Kirungu JN, Lu H, Cai X, Zhou Z, Wei Y, Wang X, Zhang Z, Peng R, Wang K, Liu F. Genome-wide analysis of multidrug and toxic compound extrusion (MATE) family in Gossypium raimondii and Gossypium arboreum and its expression analysis under salt, cadmium, and drought stress. G3. 2018; 8:2483-2500.

25. Magalhaes JV, Liu J, Guimarães CT, Lana UGP, Kochian LV. A gene in the multidrug and toxic compound extrusion (MATE) family confers aluminum tolerance in sorghum. Nat Genet. 2007;39:1156-61.

26. Marinova K, Pourcel L, Weder B, Schwarz M, Barron D, Routaboul J M, Debeaujon I, Klein M. The Arabidopsis MATE transporter TT12 acts as a vacuolar flavonoid/ $\mathrm{H}^{+}$-antiporter active in proanthocyanidin-accumulating cells of the seed coat. Plant Cell. 2007; 19:2023-2038.

27. Masaharu Suzuki, Yutaka Sato, Shan Wu, Byung-Ho Kang, Donald R. Conserved functions of the MATE transporter BIG EMBRYO1 in regulation of lateral organ size and initiation rate. Plant Cell. 2015;4:25.

28. Morita M, Shitan N, Sawada K, Van Montagu M C E, Inzé D, Rischer H, Goossens A, Oksman-Caldentey K, Moriyama Y, Yazaki K... Vacuolar transport of nicotine is mediated by a multidrug and toxic compound extrusion (MATE) transporter in Nicotiana tabacum 2009.

29. Morita Y. NorM, a putative multidrug efflux protein, of Vibrio parahaemolyticus and its homolog in Escherichia coli. Antimicrob Agents Chemother. 1998;42:1778

30. Mou S, Liu Z, Guan D, Qiu A, Lai Y, He S. Functional analysis and expressional characterization of rice ankyrin repeat-containing protein, OsPIANK1, in basal defense against Magnaporthe oryzae attack. PLoS ONE. 2013;8:e59699.

31. Nambara E, Marion-Poll A. Abscisic acid biosynthesis and catabolism. Ann Rev Plant Biol. 2005;56:165-85.

32. Natasha D, Surajit B, Somnath B, Maiti MK. Expression of rice MATE family transporter OSMATE2 modulates arsenic accumulation in tobacco and rice. Plant Mol Biol. 2018:2:87. 
33. Nawrath C, Heck S, Parinthawong N, Metraux JP. EDS5, an essential component of salicylic acid-dependent signaling for disease resistance in Arabidopsis, is a member of the MATE transporter family. Plant Cell. 2002;14:275-86.

34. Otsuka M, Matsumoto T, Morimoto R, Arioka S, Omote H, Moriyama Y. A human transporter protein that mediates the final excretion step for toxic organic cations. 2006

35. Peng Z, Wang D, Wang R, Kong N, Chao Z, Yang C, Wu W, Ma H, Qin C. Genome-wide analysis of the potato Hsp20 gene family: identification, genomic organization and expression profiles in response to heat stress. BMC Genomics. 2018;19:61.

36. Qin P, Zhang G, Hu B, Wu J, Chen W, Ren Z, Liu Y, Xie J, Yuan H, Tu B, Ma $B$, Wang $Y$, Ye L, Li L, Xiang C, Li S. Leaf-derived ABA regulates rice seed development via a transporter-mediated and temperature-sensitive mechanism. Sci Adv. 2021;7:22.

37. Radchenko M, Nie R, Lu M. Disulfide cross-linking of a multidrug and toxic compound extrusion transporter impacts multidrug efflux. J Biol Chem. 2016;291:9818-26.

38. Ricardo PD, Malgorzata R, Jorge PD, Hugo PC, José A. VvMATE1 and VVMATE2 encode putative proanthocyanidin transporters expressed during berry development in Vitis vinifera L. Plant Cell Rep. 2014;28:647.

39. Rogers E E, Guerinot M L. FRD3, a member of the multidrug and toxin efflux family, controls iron deficiency responses in Arabidopsis. Plant Cell. 2002;14:1787-99.

40. Roschzttardtz H, Seguela-Arnaud M, Briat J F, Vert G, Curie C. The FRD3 citrate effluxer promotes iron nutrition between symplastically disconnected tissues throughout Arabidopsis development. Plant Cell. 2011; 23:2725-37.

41. Rui W, Liu X, Shuang L, Ge Q, Li Y, Shao J, Qi Y, An L, Fei Y. A subgroup of MATE transporter genes regulates hypocotyl cell elongation in Arabidopsis. J Exp Bot. 2015;20:8.

42. Santos ALD, Chaves-Silva S, Yang L, Maia LGS, Chalfun-Júnior A, Sinharoy S, Zhao J, Benedito VA. Global analysis of the MATE gene family of metabolite transporters in tomato. BMC Plant Biol. 2017;17:185.

43. Serrano M, Wang B, Aryal B, Garcion C, Abou-Mansour E, Heck S, Geisler M, Mauch F, Nawrath C, Metraux JP. Export of salicylic acid from the chloroplast requires the multidrug and toxin extrusion-like transporter EDS5. Plant Physiol. 2013;162:1815-21.

44. Sun X, Gilroy EM, Chini A, Nurmberg PL, Hein I, Lacomme C, Birch PRJ, Hussain A, Loake B, Y A G. ADS1 encodes a MATE-transporter that negatively regulates plant disease resistance. New Phytol. 2011;192:471-82.

45. Taylor JS, Raes J. Duplication and divergence: the evolution of new genes and old ideas. Ann Rev Genet. 2004;5:615-43.

46. Terada T, Inui KI. Physiological and pharmacokinetic roles of $\mathrm{H}^{+} /$organic cation antiporters (MATE/SLC47A). Biochem Pharmacol. 2008;75:1689-96.

47. Thompson EP, Wilkins C, Demidchik V, Davies JM, Glover BJ. An Arabidopsis flavonoid transporter is required for anther dehiscence and pollen development. J Exp Bot. 2010;61:439-51.

48. Tiwari M, Sharma D, Singh M, Tripathi RD, Trivedi PK. Expression of OSMATE1 and OSMATE2 alters development, stress responses and pathogen susceptibility in Arabidopsis. Sci Rep. 2014;4:3964.

49. Tsubasa S, Koji I, Yoshiaki Y, Yasutaka S, Hisabumi T, Nobukazu S, Kazufumi Y, Yumi G, Kiminori T, Ken M, Takashi H. Multidrug and toxic compound extrusion-type transporters implicated in vacuolar sequestration of nicotine in tobacco roots. Plant Physiol. 2009;149:708-18.

50. Ullrich KJ. Specificity of transporters for organic anions and organic cations in the kidney. Biochim Biophys Acta. 1994; 1197:45-62.

51. Voorrips RE. MapChart: software for the graphical presentation of linkage maps and QTLs. J Heredity. 2002;93:77-8.

52. Wang L, Bei X, Gao J, Li Y, Yan Y, Hu Y. The similar and different evolutionary trends of MATE family occurred between rice and Arabidopsis thaliana. BMC Plant Biol. 2016;16:207.

53. Wang Y, Tang H, Debarry JD, Tan X, Li J, Wang X, Lee TH, Jin H, Marler B, Guo H, Kissinger JC, Paterson AH. MCScanX: a toolkit for detection and evolutionary analysis of gene synteny and collinearity. Nucleic Acids Res. 2012;40:e49.

54. Wang Z, Qian C, Guo X, Liu E, Mao K, Mu C, Chen N, Zhang W, Liu H. ELS1, a novel MATE transporter related to leaf senescence and iron homeostasis in Arabidopsis thaliana. Biochem Biophys Res Commun. 2016:476:319-25

55. Wilkins MR, Gasteiger E, Bairoch A, Sanchez JC, Williams KL, Appel RD, Hochstrasser DF. Protein identification and analysis tools in the ExPASy server. Methods Mol Biol. 1999;112:531-52.

56. Xue SX. A MATE transporter gene of Zea mays regulates leaf senescence, hypocotyl elongationand seed size. Northwest A\&F University; 2017.

57. Yamaguchi-Shinozaki K, Shinozaki K. Organization of cis-acting regulatory elements in osmotic and cold-stress-responsive promoters. Trends Plant Sci. 2005;10:88-94.

58. Yokosho K, Yamaji N, Jian FM. An Al-inducible MATE gene is involved in external detoxification of Al in rice. Plant J Cell Mol Biol. 2011;68:1061-9.

59. Yokosho K, Yamaji N, Ueno D, Mitani N, Ma JF. OsFRDL1 is a citrate transporter required for efficient translocation of iron in rice. Plant Physiol. 2009; 149:297-305.

60. Yokosho K, Yamaji N, Fujii-Kashino M, Ma JF. Functional analysis of a mate gene osfrdl2 revealed its involvement in al-induced secretion of citrate, but a lower contribution to Al tolerance in rice. Plant Cell Physiol. 2016:57:976-85.

61. Zhang X, Cherrington NJ, Wright SH. Molecular identification and functional characterization of rabbit MATE1 and MATE2-K. Am J Physiol Renal Physiol. 2007;293:F360-70.

62. Zhao J, Dixon RA. MATE transporters facilitate vacuolar uptake of epicatechin 3'-O-glucoside for proanthocyanidin biosynthesis in Medicago truncatula and Arabidopsis. Plant Cell. 2009;21:2323-40.

63. Zhao J, Huhman D, Shadle G, He XZ, Sumner LW, Tang Y, Dixon RA. MATE2 mediates vacuolar sequestration of flavonoid glycosides and glycoside malonates in Medicago truncatula. Plant Cell. 2011;23:1536-55.

64. Zhu H, Wu J, Jiang Y, Jin J, Zhou W, Wang Y, Han G, Zhao Y, Cheng B. Genomewide analysis of MATE-type gene family in maize reveals microsynteny and their expression patterns under aluminum treatment. J Genet. 2016;95:691-704.

\section{Publisher's Note}

Springer Nature remains neutral with regard to jurisdictional claims in published maps and institutional affiliations.
Ready to submit your research? Choose BMC and benefit from:

- fast, convenient online submission

- thorough peer review by experienced researchers in your field

- rapid publication on acceptance

- support for research data, including large and complex data types

- gold Open Access which fosters wider collaboration and increased citations

- maximum visibility for your research: over $100 \mathrm{M}$ website views per year

At BMC, research is always in progress.

Learn more biomedcentral.com/submissions 